\title{
The Anti-Cancer Effect of Four Curcumin Analogues on Human Glioma Cells
}

\author{
Siou-Min Luo (1D) \\ Yi-Ping $\mathrm{Wu}^{2}$ \\ Li-Chun Huang ${ }^{2}$ \\ Shih-Ming Huang ${ }^{1,2}$ \\ Dueng-Yuan Hueng (iD) ${ }^{1-3}$ \\ 'Graduate Institute of Medical Sciences, \\ National Defense Medical Center, Taipei, \\ Taiwan, Republic of China; ${ }^{2}$ Department \\ of Biochemistry, National Defense \\ Medical Center, Taipei, Taiwan, Republic \\ of China; ${ }^{3}$ Department of Neurological \\ Surgery, Tri-Service General Hospital, \\ National Defense Medical Center, Taipei, \\ Taiwan, Republic of China
}

Purpose: Glioblastoma multiforme (GBM) is the primary aggressive malignancy of the brain with poor outcome. Curcumin analogues are polyphenolic compounds as the bioactive substances extracted from turmeric. This study aims to investigate the anti-cancer effects of four curcumin analogues. Furthermore, the molecular mechanisms of dimethoxycurcumin in human gliomas were analyzed by Western blot.

Materials and Methods: Human LN229 and GBM8401 glioma cells were treated by four curcumin analogues with different number of methoxy groups. The cell viability, cell cycle, apoptosis, proliferation and ROS production of human gliomas were analyzed by flow cytometry. Moreover, the effects of four curcumin analogues on tumorigenesis of gliomas were conducted by wound healing assay and colony formation assay. Furthermore, the molecular mechanisms of dimethoxycurcumin in human gliomas were analyzed by Western blot.

Results: Our data showed that four different curcumin analogues including curcumin, bisdemethoxycurcumin, demethoxycurcumin, and dimethoxycurcumin promote sub-G1 phase, G2/M arrest, apoptosis, and ROS production in human glioma cells. Moreover, dimethoxycurcumin suppressed cell viability, migration, and colony formation, induction of sub-G1, G2/M arrest, apoptosis, and ROS production in glioma cells. Moreover, the mechanism of dimethoxycurcumin is ROS production to increase LC3B-II expression to induce autophagy. Furthermore, dimethoxycurcumin suppressed apoptotic marker, BCL-2 to promote apoptosis in LN229 and GBM8401 glioma cells.

Conclusion: Our study found that dimethoxycurcumin induced apoptosis, autophagy, ROS production and suppressed cell viability in human gliomas. Dimethoxycurcumin might be a potential therapeutic candidate in human glioma cells.

Keywords: curcumin, bisdemethoxycurcumin, demethoxycurcumin, dimethoxycurcumin, glioblastoma

\section{Introduction}

Glioblastoma multiforme (GBM) is the primary aggressive malignancy of the brain. Current standard treatment includes concurrent chemoradiotherapy after surgical resection methods have been the treatments. ${ }^{1}$ Since the cell biology of human glioma possesses invasiveness, angiogenesis, and high proliferation leading to poor survival. ${ }^{2,3}$ Therefore, the study of a new compound to improve cell biology in patients with glioblastomas is mandatory.

Curcuminoids have many pharmacological activities used in Ayurvedic and Chinese medicine for centuries. ${ }^{4}$ Curcumin can pass through the blood-brain barrier (BBB) and is detectable in cerebrospinal fluid of mouse model. ${ }^{5}$ Curcumin, which is reported to
Correspondence: Dueng-Yuan Hueng Department of Neurological Surgery, Tri-Service General Hospital, Nationa Defense Medical Center, Taipei, Taiwan, Republic of China

Tel +886-2-8792-3100 \#18802

Email hondy2195@yahoo.com.tw 
target several signaling pathways mediated by p53, Ras, PI3K, and AKT in breast cancer. ${ }^{6}$ Curcumin induced G2/M phase arrest and suppresses $\mathrm{Wnt} / \beta$-catenin signaling pathway to reduce cell proliferation in medulloblastoma. ${ }^{7}$ Curcuminoids belong to polyphenolic compounds containing about $77 \%$ pure curcumin (Cur), 17\% demethoxycurcumin (DMC) and 3\% bisdemethoxycurcumin (BisDMC). Curcuminoids are bioactive substances extracted from turmeric (Curcuma longa Linn). ${ }^{8}$ A previous study reported that demethoxycurcumin increases lung cancer cell DNA damage to reduce DNA repair-related proteins. ${ }^{9}$ Demethoxycurcumin suppresses NF- $\kappa$ B pathways to inhibit migration and invasion in HeLa cells. ${ }^{10}$ Bisdemethoxycurcumin inhibits PI3K/AKT signaling to sensitize chemotherapy in cisplatin-resistant lung cancer cells. ${ }^{11}$ Bisdemethoxycurcumin inhibits ovarian cancer cell through MMPs expressions to reduce oxidative stress. ${ }^{12}$ Bisdemethoxycurcumin inactive AKT to inhibit the proliferation of hepatocellular carcinoma through CYLDmediated deubiquitination. ${ }^{13}$ Curcumin, demethoxycurcumin, and bisdemethoxycurcumin induce caspase dependent and -independent apoptosis through activating Smad 2/3 or repressing AKT pathway in osteosarcoma, breast cancer and melanoma cell lines. ${ }^{14}$ Furthermore, these three analogues are through ROS-independent mechanism differentially regulate anti-inflammatory and anti-proliferative responses in lymphoma, lung adenocarcinoma, breast cancer, prostate cancer, and so on. ${ }^{8}$

Many journals have proved that curcumin still has some clinical limitations, such as metabolic instability, poor bioavailability, and poor hydrophilic. ${ }^{15,16}$ One of the many solutions for improve curcumin treatment dilemmas is the use of synthetic analogues. ${ }^{16}$ As shown in Figure 1A, the structures for these four curcumin analogues are illustrated. Curcumin has two methoxy group and two hydroxyl group, and demethoxycurcumin is lacking a methoxy group on a benzene ring on curcumin, ${ }^{14}$ both curcumin and demethoxycurcumin are less stable than bisdemethoxycurcumin, which lacks two methoxy groups on curcumin aromatic ring. ${ }^{8}$ Dimethoxycurcumin (DiMC), a synthetic analog of curcumin, has four methoxy groups and lacks the phenolic-OH group in comparison to the curcumin, ${ }^{16}$ and it is reported to possess inter-related anti-cancer and pro-oxidant activity. ${ }^{17}$ Dimethoxycurcumin is a stable metabolic analogue of curcumin capable of therapeutic potential because of its pharmacological and biological effects. ${ }^{18}$ Moreover, dimethoxycurcumin is more hydrophobic than curcumin in terms of its structure. ${ }^{16}$ However, the effect of dimethoxycurcumin on glioblastoma cells remains to be clarified.

In this study, we compared the effect of four different curcumin analogues: curcumin, bisdemethoxycurcumin, demethoxycurcumin, and dimethoxycurcumin on gliomas. Specifically, we aim to investigate the anti-cancer effects of four curcumin analogues, and further investigate the biological activity and molecular mechanism of dimethoxycurcumin in LN229 and GBM8401 glioma cells.

\section{Materials and Methods Curcumin Analogues}

Curcumin, Sigma-Aldrich Chemie GmbH: Munich, Germany, CAS Number: 458-37-7., Bisdemethoxycurcumin, Cayman, CAS Number 33171-05-0., Demethoxycurcumin, Cayman, CAS Number 22608-11-3., Dimethoxycurcumin, Cayman, CAS Number 160096-59-3.

\section{Cell Culture and Cell Viability Assays}

The source of normal brain cell line SVG p12 and LN229 glioma cell line purchased from American Type Culture Collection (ATCC). NHA (normal human astrocyte) purchased from Gibco (cat N7805-100 (K1884)). Dr. WeiHwa Lee characterized GBM8401 glioma cell line. ${ }^{19}$ GBM8401 glioma cell line was sourced commercially from Bioresource Collection and Research Center (BCRC number: 60163, Hsinchu, Taiwan).

SVG p12 cells maintained in Eagle's Minimum Essential media (MEM, Corning, USA REF:10-009-CV), and NHA cells cultured in contain 1\% N-2 Supplement (Gibco, REF 17502-408) 4.5g/mL glucose Dulbecco's modified Eagle's medium (DMEM, Corning, USA REF: 10-013-CV) with. LN229 cells cultured in $1 \mathrm{~g} / \mathrm{mL}$ glucose Dulbecco's modified Eagle's medium (DMEM, Corning, USA REF: 10-014-CV) and GBM8401 cells were maintained in $4.5 \mathrm{~g} / \mathrm{mL}$ glucose Dulbecco's modified Eagle's medium (DMEM). All mediums contained 10\% fetal bovine serum (FBS, Gibco USA REF 10437-028), penicillin, and streptomycin (Corning, USA REF: 30-004-CI) at $37^{\circ} \mathrm{C}$ under $5 \% \mathrm{CO}_{2}$ and $95 \%$ air.

To assess cell viability, glioma cell lines were plated in 96-well plates at a density of 3000 cells per well in SVG p12, NHA, and LN229. 2000 cells per well in GBM8401 treated with each 4 curcumin analogues for $24 \mathrm{~h}$. Briefly, cells were incubated for $2 \mathrm{~h}$ in each medium $(200 \mu \mathrm{L})$ supplemented with CellTiter 96 Aqueous One Solution Reagent (Promega, Madison, WI, USA) MTS solution 
A<smiles>[R16]c1ccc(C=CC(=O)/C(C)=C/c2ccc([R])c([R])c2)cc1[R2]</smiles>

Curcumin

Bis-demethoxy-curcumin

Demethoxy-curcumin

Dimethoxy-curcumin

B

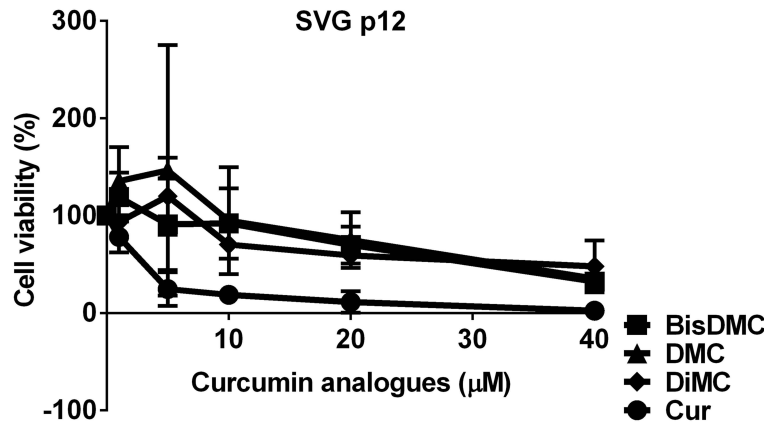

D

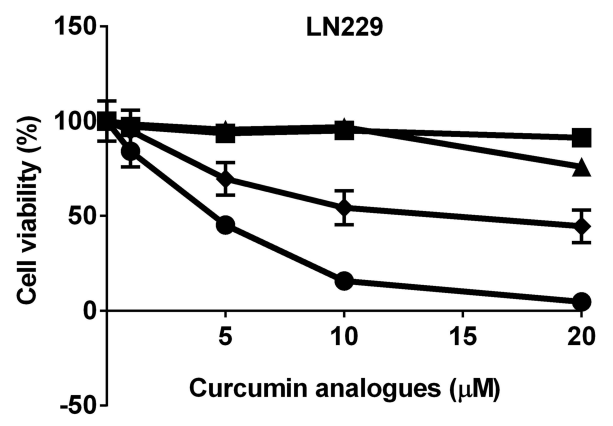

$\mathbf{R 2}$

$-\mathrm{OCH}_{3}$

$-H$

$-\mathbf{H}$

$-\mathrm{H} \quad-\mathrm{OCH}_{3}$

$-\mathrm{OCH}_{3} \quad-\mathrm{OCH}_{3}$

C
R4

R3

$-\mathrm{OH}$

-OH

-OH

$-\mathrm{OH}$

-OH $\quad-\mathrm{OH}$

$-\mathrm{OCH}_{3} \quad-\mathrm{OCH}_{3}$

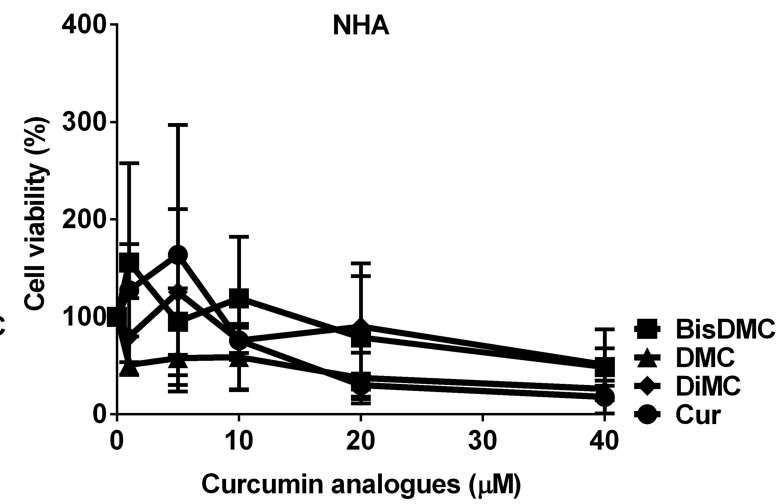

E

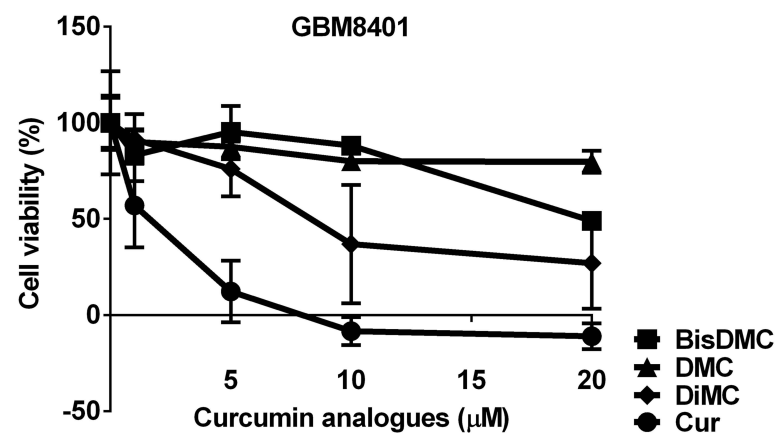

Figure I The effect of curcumin analogues on cell viability of normal brain cell controls and glioma cells. (A) The structure of curcumin analogues. (B and C) The effect of curcumin analogues on cell viability of normal brain cell controls assessed by MTS assay after $24 \mathrm{~h}$ treatment. (D and $\mathbf{E})$ The effect of curcumin analogues on cell viability of glioma cells assessed by MTS assay after $24 \mathrm{~h}$ treatment. 
(20 $\mu \mathrm{L} /$ well), measured at $490 \mathrm{~nm}$ by using a Molecular Devices SpectraMax 190 Microplate Reader.

\section{Cell Cycle and Proliferation Assays}

For cell cycle analysis, glioma cells were fixed in $70 \%$ ethanol at $4{ }^{\circ} \mathrm{C}$ and kept overnight at $-20^{\circ} \mathrm{C}$. The cells were then washed twice with contained 1\% FBS cold PBS and stained with propidium iodide (PI) solution (BIOTIUM; cat.40017, $50 \mathrm{mg} / \mathrm{mL}$ PI in PBS, 1\% Tween 20, and $10 \mathrm{mg} / \mathrm{mL}$ RNase A) for $30 \mathrm{~min} 37^{\circ} \mathrm{C}$ in the dark. The DNA content of the cells was measured using fluorescence-activated cell sorting (BD Biosciences, San Jose, CA, USA). Glioma cell proliferation was assayed using FITC-59-bromo-29-deoxyuridine (Brd U) flow kits according to the manufacturer's instructions (BD Biosciences, cat.51-2354AK). The percentage of positive glioma cells was determined using flow cytometry.

\section{Apoptosis Assays and ROS Detected Assays}

To evaluate the incidence of apoptosis, we used the PE Annexin V Apoptosis Detection Kit I according to the manufacturer's instructions (BD Biosciences San Jose, CA, USA, cat.559763). Briefly, glioma cells were seeded into 6-well dishes at a density of $1 \times 10^{5}$ cells per well. Stained cells were detected using Annexin V-FITC/ 7-AAD. The cells were categorized into 3 groups: viable (annexin $\mathrm{V}^{-}$and FITC $^{-}$), early apoptotic (annexin $\mathrm{V}^{+}$and FITC $^{-}$), and later apoptotic (annexin $\mathrm{V}^{+}$and FITC $^{+}$).

To detect the production of ROS, we plated $1 \times 10^{5}$ cells/ well in 6-well dishes and treated curcumin analogues in each group. After $4 \mathrm{~h}$ drug treatment, living cells stained $10 \mu \mathrm{M}$ DCFH-DA (Sigma-Aldrich) and incubated in $37^{\circ} \mathrm{C}$ for 15 min. Stained cells were determined using flow cytometry.

\section{Migration Assays and Colony Formation Assays}

Glioma cells in each group were plated in 12-well plates at a density of $1 \times 10^{5}$ cells per well and grown at $37^{\circ} \mathrm{C}$ in a $5 \% \mathrm{CO}_{2}$ incubator. We removed the medium when cell confluence reached $90 \%$ and made a wound in the monolayer with a $200 \mu \mathrm{L}$ pipette tip. To expel the non-adherent cells, we washed the plate three times. The wound area was photographed immediately after wounding $(0 \mathrm{~h})$ and at $16 \mathrm{~h}$ post wounding. The migration rates were computed according to the change of wound area measured by ImageJ software (NIH, Bethesda, MD).
Glioma cells were plated in 6-well plates at a density of 3000 cells per well and cultured for 2 weeks. Day 3 treated with curcumin analogues. The colonies were then fixed with methanol and stained with $0.5 \%$ crystal violet. Colonies were measured by Image $\mathbf{J}$ software (National Institutes of Health, Bethesda, MD, USA), and those larger than $0.1 \mathrm{~mm}$ in diameter were counted.

\section{Cell Lysate Preparation and Western Blots}

Cells were lysed by RIPA buffer (100 mM Tris-HCl, 150 $\mathrm{mM} \mathrm{NaCl}$, and $0.1 \%$ SDS, and $1 \%$ Triton-X-100) at $4^{\circ} \mathrm{C}$ for $10 \mathrm{~min}$, and the cell lysates were harvested by centrifugation at $15,000 \mathrm{rpm}$ for $10 \mathrm{~min}$ to obtain the supernatants. Twenty-microgram cell lysates from each group were applied to $8 \%$ and $12 \%$ sodium dodecyl sulfate polyacrylamide gels electrophoresis. Proteins were transferred onto polyvinyl difluoride membranes (Millipore, MA, USA) and blocked with 5\% skim milk in TBST for $1 \mathrm{~h}$ at room temperature. The antibodies used are ACTN (Santa Cruz Technology Dallas, TX, USA; SC-17829), p-mTOR (Cell Signaling Technology, Danvers, MA, USA; CST-2971), mTOR (Cell Signaling Technology, Danvers, MA, USA; CST-2972), p-AKT (Cell Signaling Technology, Danvers, MA, USA; CST-9271), AKT (Cell Signaling Technology, Danvers, MA, USA; CST-4691), p-ERK (Cell Signaling Technology, Danvers, MA, USA; CST-4370), ERK (Cell Signaling Technology, Danvers, MA, USA; CST-4695), p62 (Santa Cruz Technology Dallas, TX, USA; SC- 28359), LC3B (Cell Signaling Technology, Danvers, MA, USA; CST2775), BCL2 (Cell Signaling Technology, Danvers, MA, USA; CST-4223), p-CDC2 (Thr15) (Cell Signaling Technology, Danvers, MA, USA; CST-9111) and CDC2 (Cell Signaling Technology, Danvers, MA, USA; CST9112). Band detection was conducted by enhanced chemi-luminescence and X-ray film (GE Healthcare, Piscataway, NJ, USA).

\section{Statistical Analysis}

Statistical analyses and figures were used GraphPad Prism 6 software (San Diego, CA, USA). We used a Student's $t$ test or one-way ANOVA to compare differences between the experimental and control groups. Statistical significance was set at $* \mathrm{P}<0.05, * * \mathrm{P}<0.01$, and $* * * \mathrm{P}<0.001$ 


\section{Results}

\section{The Effects of Curcumin Analogues on Cell Viability}

First, we investigated the effect of curcumin analogues on cell viability of normal brain cells and glioma cells. We assessed the $24 \mathrm{~h}$ cell viability of human normal brain cells and glioma cell lines by MTS assay (Figure 1B-E), the $\mathrm{IC}_{50}$ of curcumin was $4.19 \mu \mathrm{M}$ in SVG p12, $22.15 \mu \mathrm{M}$ in NHA, $5.85 \mu \mathrm{M}$ in LN229 and 6.31 $\mu \mathrm{M}$ in GBM8401, 29.15 $\mu \mathrm{M}, 31.88 \mu \mathrm{M}, 24.54 \mu \mathrm{M}$ and $17.73 \mu \mathrm{M}$ in SVG p12, NHA, LN229 and GBM8401 for demethoxycurcumin, $30.03 \mu \mathrm{M}$, $11.32 \mu \mathrm{M}, 26.77 \mu \mathrm{M}$ and $32.43 \mu \mathrm{M}$ in SVG p12, NHA, LN229 and GBM8401 for bisdemethoxycurcumin, and $29.55 \mu \mathrm{M}, 28.28 \mu \mathrm{M}, 18.99 \mu \mathrm{M}$ and $16.82 \mu \mathrm{M}$ for dimethoxycurcumin in SVG p12, NHA, LN229 and GBM8401 (Table 1). The $\mathrm{IC}_{50}$ of curcumin and dimethoxycurcumin are higher in NHA than in glioma cells. The $\mathrm{IC}_{50}$ of demethoxycurcumin is higher in SVG p12 than in glioma cells. The results showed that dimethoxycurcumin has more cytotoxic to gliomas. Moreover, the cytotoxicity is higher in curcumin than in dimethoxycurcumin, demethoxycurcumin and bisdemethoxycurcumin.

Table I $\mathrm{IC}_{50}$ for Curcumin Analogues on Normal Brain Cell Controls and Glioma Cells

\begin{tabular}{|l|r|r|}
\hline Drug Name & Cell Line & IC $_{\mathbf{5 0}}(\boldsymbol{\mu M})$ \\
\hline Curcumin & SVG pI2 & 4.19 \\
& NHA & 22.15 \\
& LN229 & 5.85 \\
& GBM840I & 6.31 \\
\hline Bisdemethoxycurcumin & SVG pI2 & 29.15 \\
& NHA & 31.88 \\
& LN229 & 26.77 \\
& GBM840I & 32.43 \\
\hline Demethoxycurcumin & SVG PI2 & 30.03 \\
& NHA & 11.32 \\
& LN229 & 24.54 \\
& GBM840I & 17.73 \\
\hline Dimethoxycurcumin & SVG pI2 & 29.55 \\
& NHA & 28.28 \\
& LN229 & 18.99 \\
& GBM840I & 16.82 \\
\hline
\end{tabular}

Abbreviations: Cur, curcumin; BisDMC, bisdemethoxycurcumin; DMC, demethoxycurcumin; DiMC, dimethoxycurcumin; BBB, blood-brain barrier; ROS, reactive oxygen species; AKT, protein kinase $B$; mTOR, mammalian target of rapamycin; p62, sequestosome I; ERK, extracellular signal-regulated kinases; CDC2, cyclin-dependent kinase I; LC3B, microtubule-associated proteins IA/IB light chain 3B; BCL-2, B-cell lymphoma 2.

\section{The Effect of Curcumin Analogues on Glioma Cell Cycle}

To assess the inhibitory effect of curcumin analogues on glioma cells, we investigated effect of curcumin analogues on cell cycle after the $48 \mathrm{~h}$ treatment. The results showed that all four curcumin analogues dose-dependently increased sub-G1 and G2/M phase and reduced G1 phase in both LN229 and GBM8401 cell lines (Figure 2A and B). Flow cytometric analysis revealed that treatment with curcumin analogues for $48 \mathrm{~h}$ led to reduced G1 phase, and was accompanied by increased subG1 phase and caused G2/M phase arrest. Low-dose Bisdemethoxycurcumin increased $\mathrm{S}$ phase not significantly in GBM8401 and LN229 but had a trend (Figure 2A and B).

\section{Four Curcumin Analogues Increased Apoptosis of Glioma Cells}

Because curcumin analogues dose-dependently increased the sub-G1 cell fraction, we used 7-aminoactinomycin (7-AAD) and annexin- $\mathrm{V}$ cytometry to investigate the 48 $h$ effect of curcumin analogues on apoptosis of gliomas. The results showed that all of four curcumin analogues increased the positive staining of annexin-V cell in LN229 (Figure 3A and B) and GBM8401 (Figure 3C and D), we found that four curcumin analogues induced early- and late-stage apoptosis and that the effect was in dose dependent manner.

\section{The Effect of Curcumin Analogues on Glioma Cell Proliferation}

We further investigated the effect of curcumin analogues on cell proliferation in gliomas. Single-dose $48 \mathrm{~h}$ curcumin analogues treated with gliomas. LN229 and GBM8401 glioma cells were treated with curcumin analogues for 48 $\mathrm{h}$ in a single dose manner. The results showed that curcumin suppressed cell proliferation in LN229 and GBM8401. Demethoxycurcumin promoted cell proliferation in LN229 and reduce in GBM8401 cells. Dimethoxycurcumin did not affect the proliferation of LN229 and GBM8401 cells. However, bisdemethoxycurcumin significantly increased the cell proliferation in LN229 and GBM8401 (Figure 4A and B). Due to the increased $S$ phase and proliferation of LN229 and GBM8401 cell observed at low-dose bisdemethoxycurcumin, we further investigated the dose effect of bisdemethoxycurcumin on cell proliferation. LN299 and GBM8401 cells were treated with bisdemethoxycurcumin 
A

LN229
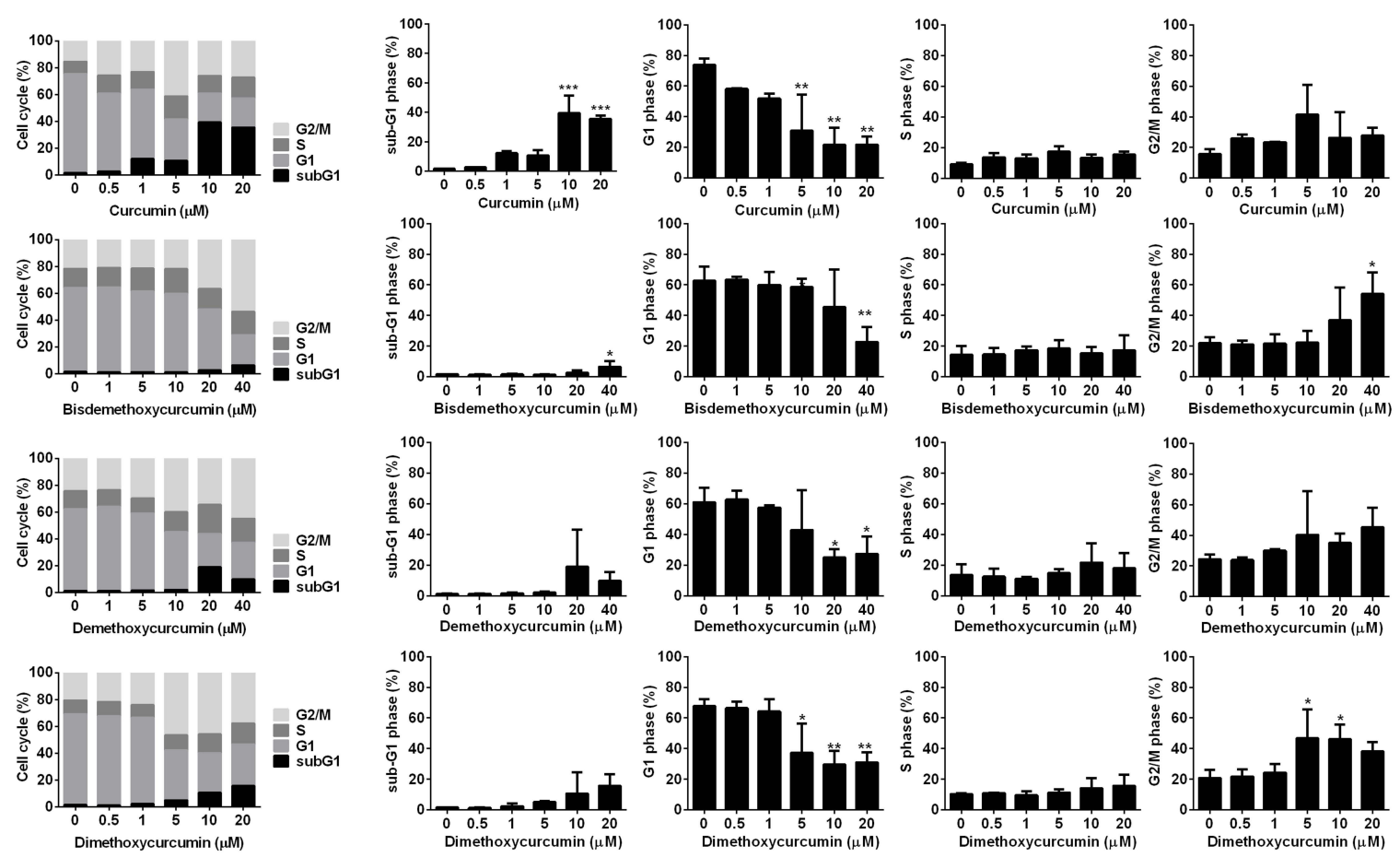

B
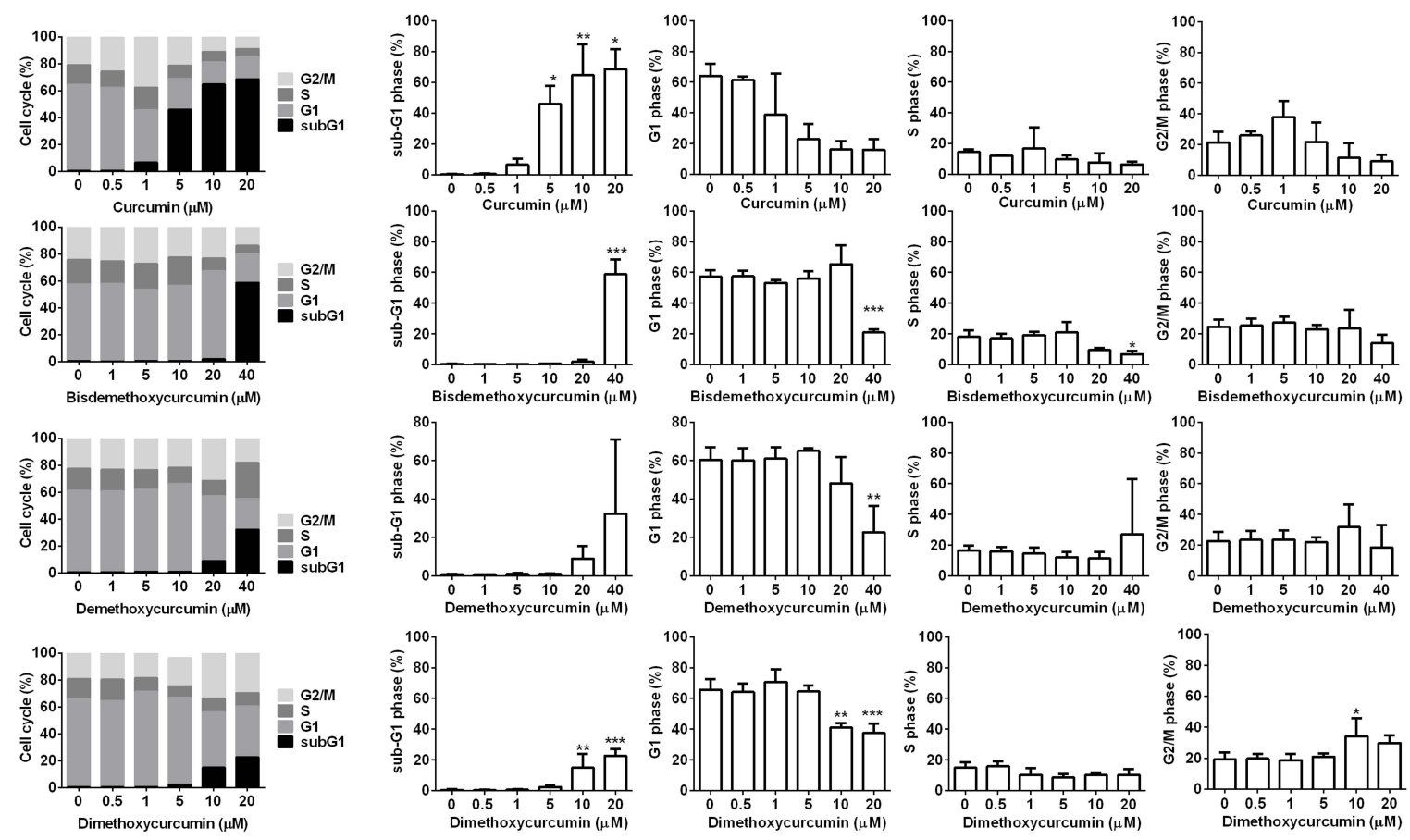

Figure 2 The effect of curcumin analogues on cell cycle of LN229 and GBM840 I glioma cell lines after 48 h treatment. (A and B) cell cycle assessed by flow cytometry upon treatment with curcumin analogues in LN229 and GBM840 I glioma cells. Bar graph showed the effect of curcumin analogues on glioma cells. Data were presented as the mean \pm s.d.; $\mathrm{n}=3$; $* \mathrm{P}<0.05$, $* * \mathrm{P}<0.0 \mathrm{l}$, $* * * \mathrm{P}<0.00 \mathrm{l}$ vs the control. 
A

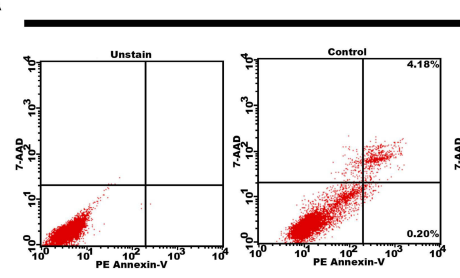

LN229
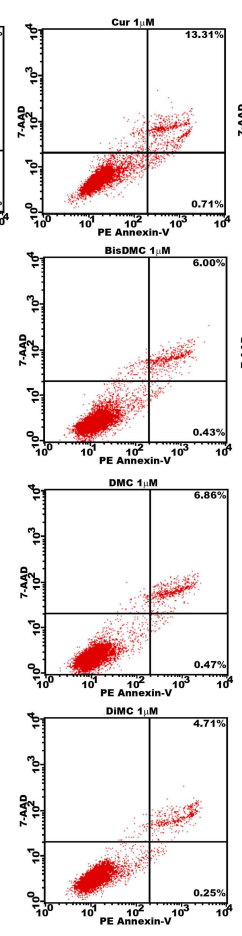

GBM8401

C

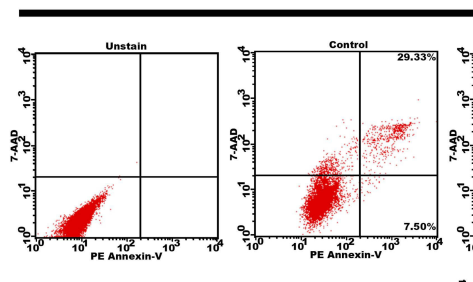

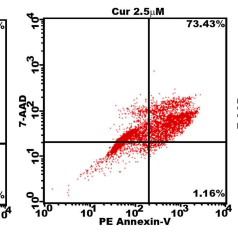
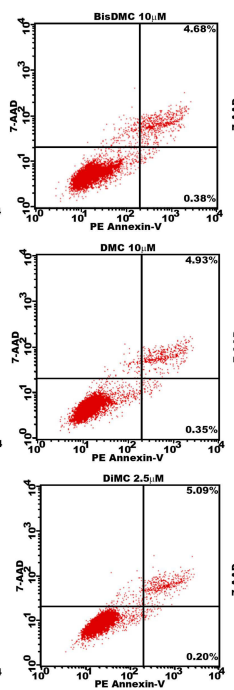
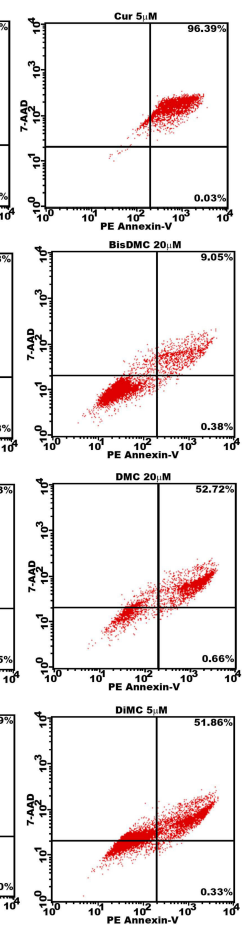

B

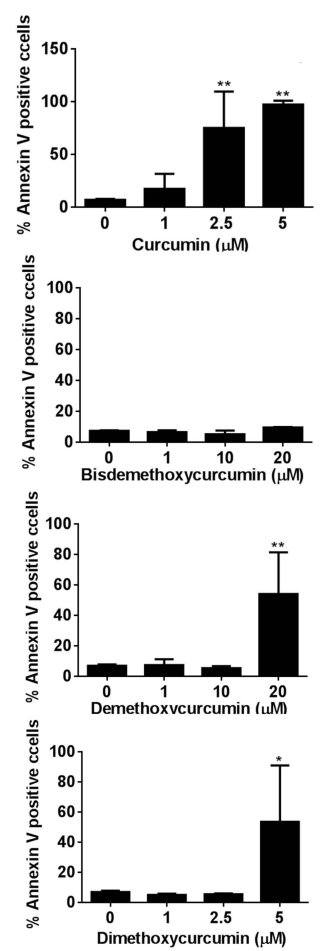

D

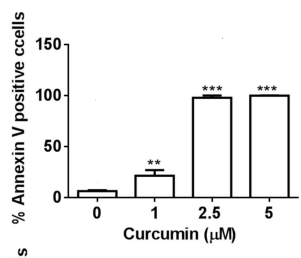

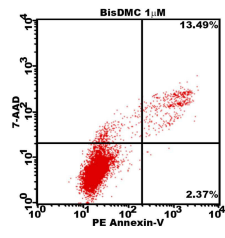
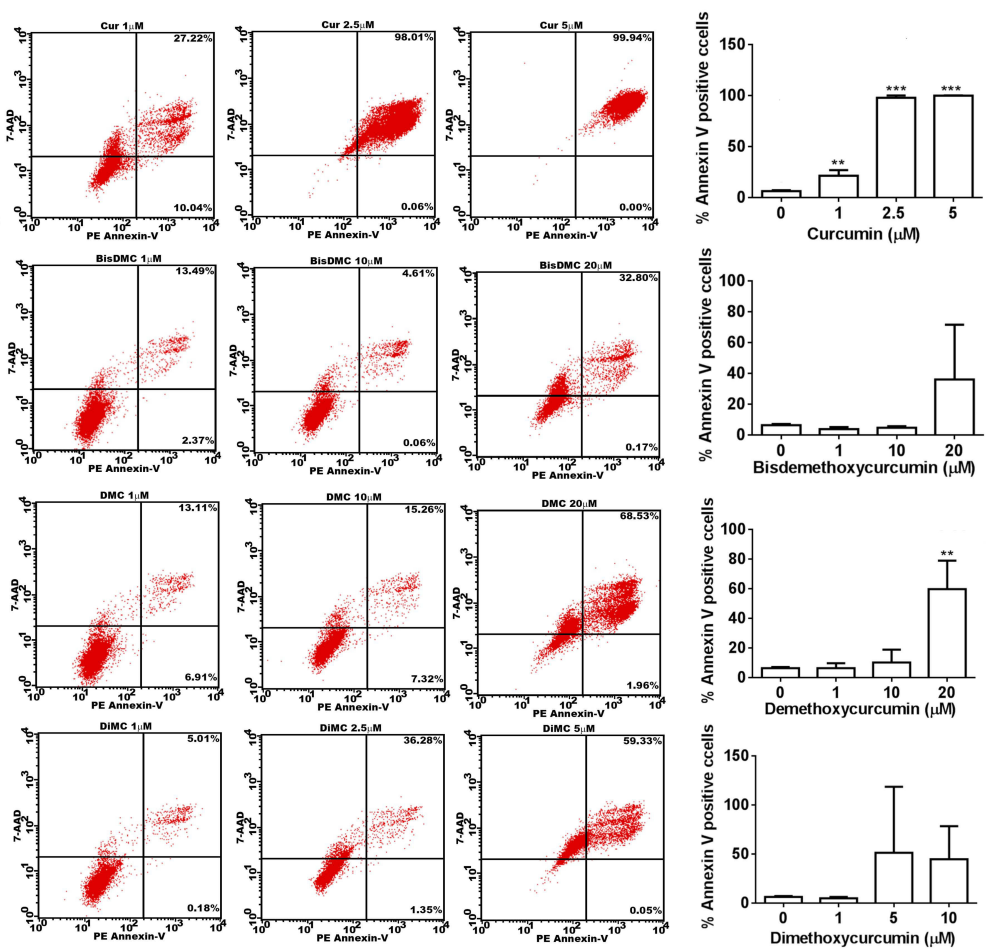

Figure 3 The effect of curcumin analogues on apoptosis of gliomas. (A and C) Images showing annexin-V positive percentage treated with curcumin analogues on LN229 and GBM840 I cells. (B and D) Bar graph showed the effect of bisdemethoxycurcumin proliferation by glioma cells. Data were presented as the mean \pm s.d.; $n=3 ; * P<0.05$, **P $<0.0$ I, ${ }^{* * *} \mathrm{P}<0.00$ I vs the control. 
A
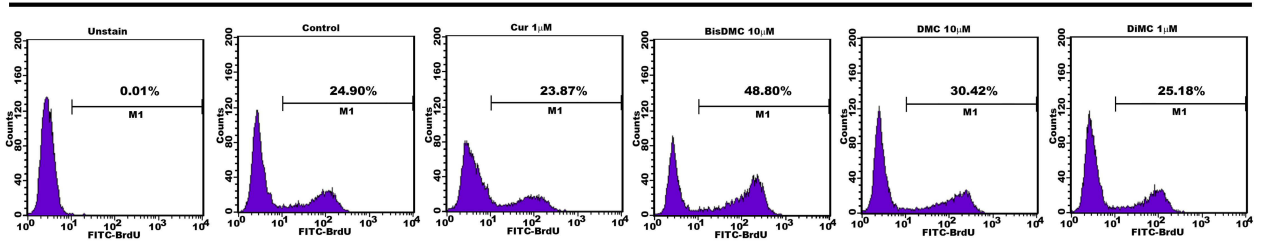

B

GBM8401
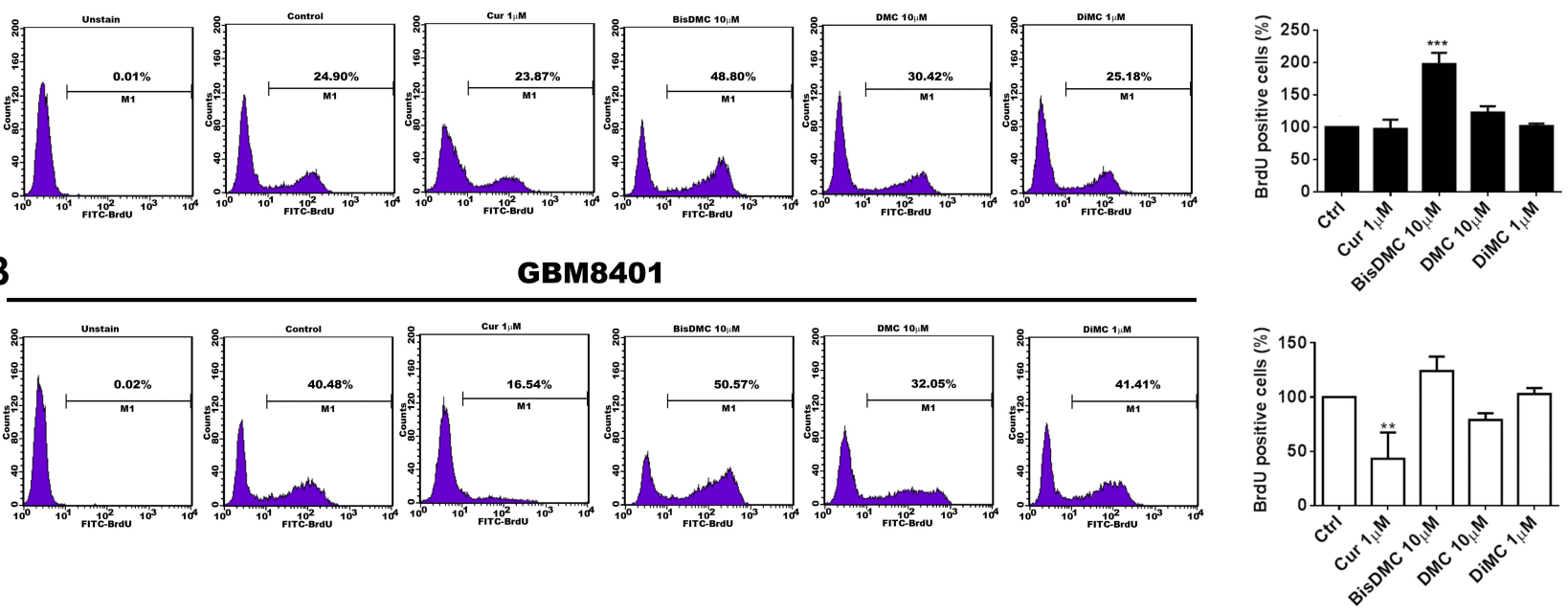

C

LN229
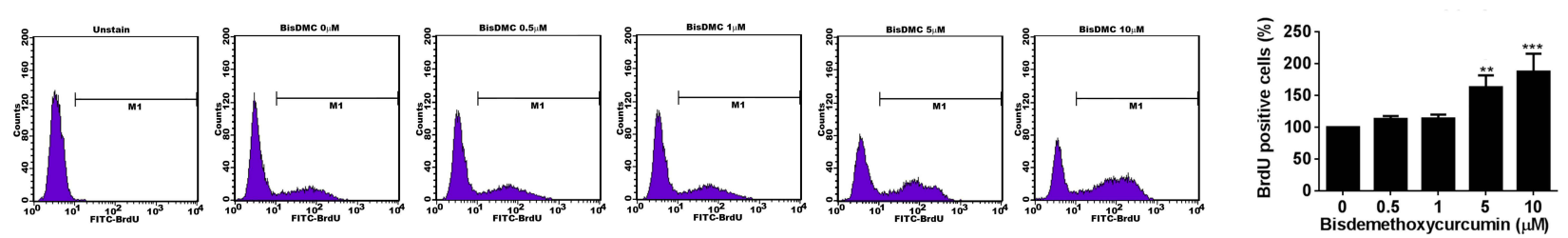

D

\section{GBM8401}
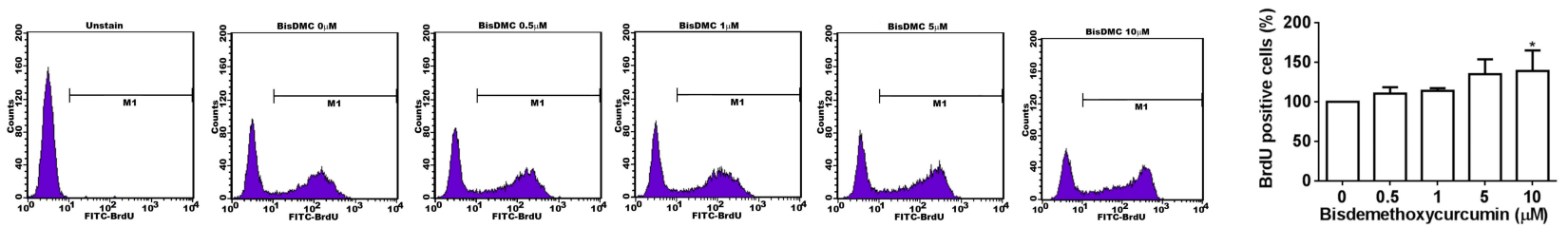

Figure 4 The effect of curcumin analogues on glioma cell proliferation. (A and B) Images showing BrdU proliferation results treated with $48 \mathrm{~h}$ curcumin analogues under $I_{50}$ in LN229 and GBM840I cells. Bar graph showing the effect of curcumin analogues proliferation on glioma cells. Data are presented as the mean \pm s.d.; $\mathrm{n}=3$; $* \mathrm{P}<0.05$, **P $<0.0$ I vs the control. (C and D) Images showing BrdU proliferation results treated with $48 \mathrm{~h}$ bisdemethoxycurcumin on LN229 and GBM840 I cells. Bar graph showing the effect of bisdemethoxycurcumin proliferation on glioma cells. Data are presented as the mean $\pm \mathrm{s}$.d.; $\mathrm{n}=3 ; * \mathrm{P}<0.05, * * \mathrm{P}<0.0 \mathrm{I}, * * * \mathrm{P}<0.00 \mathrm{I}$ vs the control.

for $48 \mathrm{~h}$ and assessed by BrdU proliferation assay, the results showed that bisdemethoxycurcumin dosedependently increased M1 in both LN299 and GBM8401 cells (Figure 4C and D).

\section{Curcumin and Dimethoxycurcumin Inhibited the Glioma Migration}

After obtained the $\mathrm{IC}_{50}$ from cell viability assay, we investigate the effect of curcumin analogues (dosage under $\mathrm{IC}_{50}$ ) on migration of human glioma cell lines assessed by wound healing assay. The results showed that curcumin dose-dependently inhibited the migration of LN229 (Figure 5A) and GBM8401 (Figure 5B). Dimethoxycurcumin inhibited migration of LN229 and
GBM8401 in high-dose manner (Figure 5G and H). But both bisdemethoxycurcumin and demethoxycurcumin had no effect on the migration of gliomas (Figure 5C-F).

\section{The Effect of Curcumin Analogues on Colony Formation of Glioma Cells}

We further investigated the effect of curcumin analogues on colony formation. As shown in Figure 6, curcumin inhibited colony formation in both LN229 and GBM8401 glioma cells. In contrast, bisdemethoxycurcumin dose dependently increased colony formation in LN229 and GBM8401, while dimethoxycurcumin suppressed LN229 and GBM8401 colony formation only in high-dose manner. Demethoxycurcumin suppressed colony formation in 

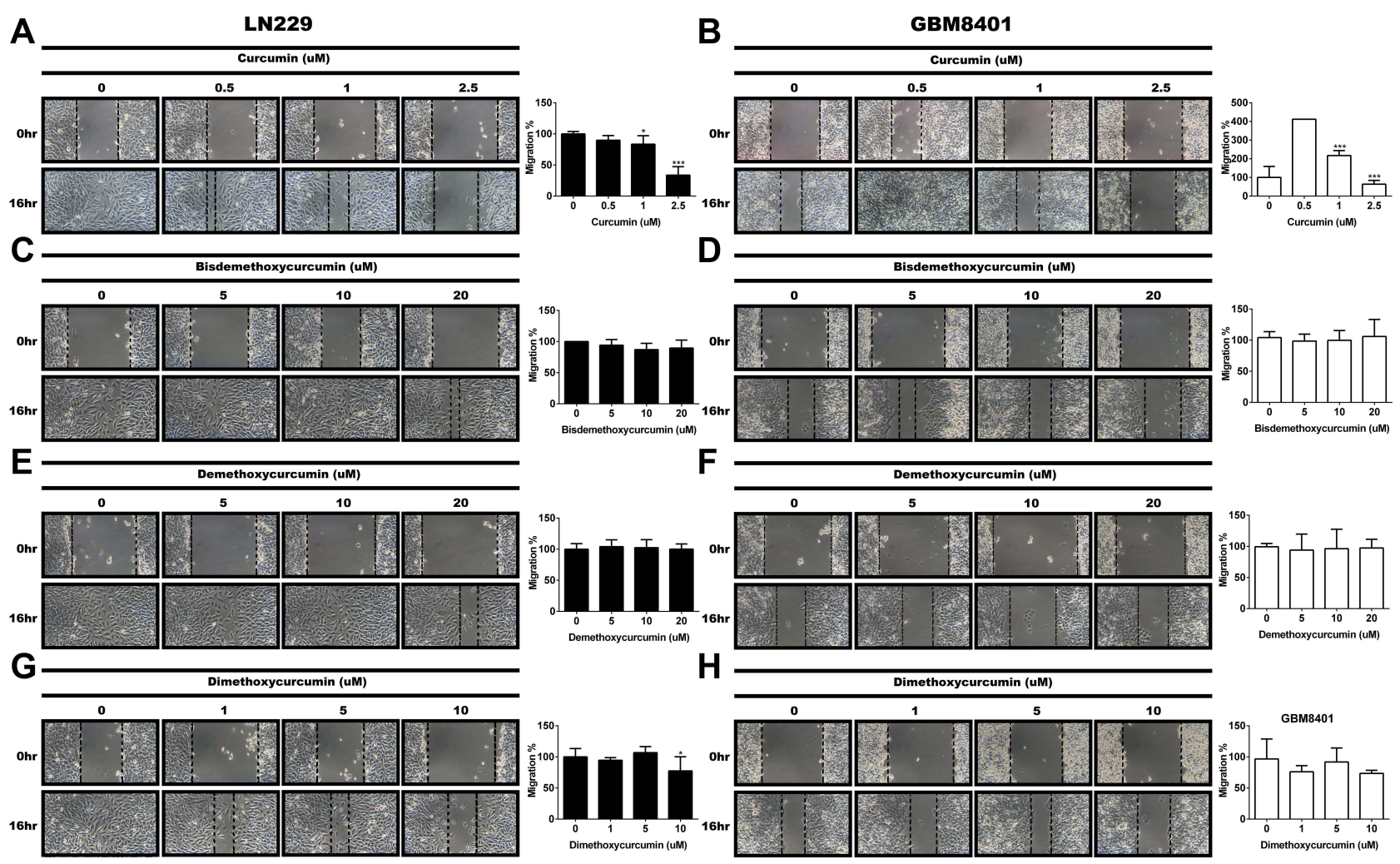

Figure 5 The effect of curcumin analogues on gliomas migration. (A and B) Migration assessment based on the decreases in wound area during $16 \mathrm{~h}$ wound healing assays treated with curcumin on LN229 and GBM840 I cells. (C and D) Migration assessment based on the decreases in wound area during $16 \mathrm{~h}$ wound healing assays treated with bisdemethoxycurcumin on LN229 and GBM840 I cells. (E and F) Migration assessment based on the decreases in wound area during $16 \mathrm{~h}$ wound healing assays treated with demethoxycurcumin on LN229 and GBM840I cells. ( $G$ and $\mathbf{H}$ ) Migration assessment based on the decreases in wound area during $16 \mathrm{~h}$ wound healing assays treated with dimethoxycurcumin on LN229 and GBM840I cells. Wound area at $0 \mathrm{~h}$ in control group (DMSO) was assigned a value of $100 \%$. $* \mathrm{P}<0.05$, $* * * \mathrm{P}<0.00 \mathrm{I}$ vs the control.

LN229 cells only in high-dose manner, but not in GBM8401 cells.

\section{Curcumin Analogues Increased ROS Production of Glioma Cells}

To investigate whether curcumin analogues affected ROS production, LN229 and GBM8401 glioma cells were treated by these four curcumin analogues for $4 \mathrm{~h}$, respectively. The results showed that the DCFH-DA picks shift to the right, indicating these four curcumin analogues dosedependently increased the ROS production in LN229 and GBM8401 glioma cells (Figure 7A and B). The dimethoxycurcumin treated LN229 was not significant but had a trend.

\section{The Mechanisms of Curcumin Analogues in the Treatment of Gliomas}

As shown in Figures 3 and 7, curcumin analogues increased early-apoptosis, late-apoptosis and ROS production in LN229 and GBM8401 glioma cells. We further investigated the mechanism for one of curcumin analogues in glioma cells (Figure 8). The results showed that dimethoxycurcumin dose-dependently reduced p-mTOR, p-CDC2, and BCL-2, while dose-dependently increased p-AKT, p-ERK, LC3B-II and p62 in LN229 and GBM8401 cells.

\section{Discussion}

Our study showed that these four curcumin analogues have anti-cancer activities, including suppression of cell viability, an increase of sub-G1, G2/M arrest, induction of apoptosis, and increase of ROS production in LN229 and GBM8401 glioma cells. To our knowledge and PubMed search found that this is the first study to investigate the effect of dimethoxycurcumin on glioblastoma cells. Moreover, this study side by side compared the anticancer activities of four curcumin analogues against glioma cells.

Our study showed that the increases of sub-G1, G2/M arrest, induction of apoptosis, and ROS production in glioma cells were observed at a lower dose of 


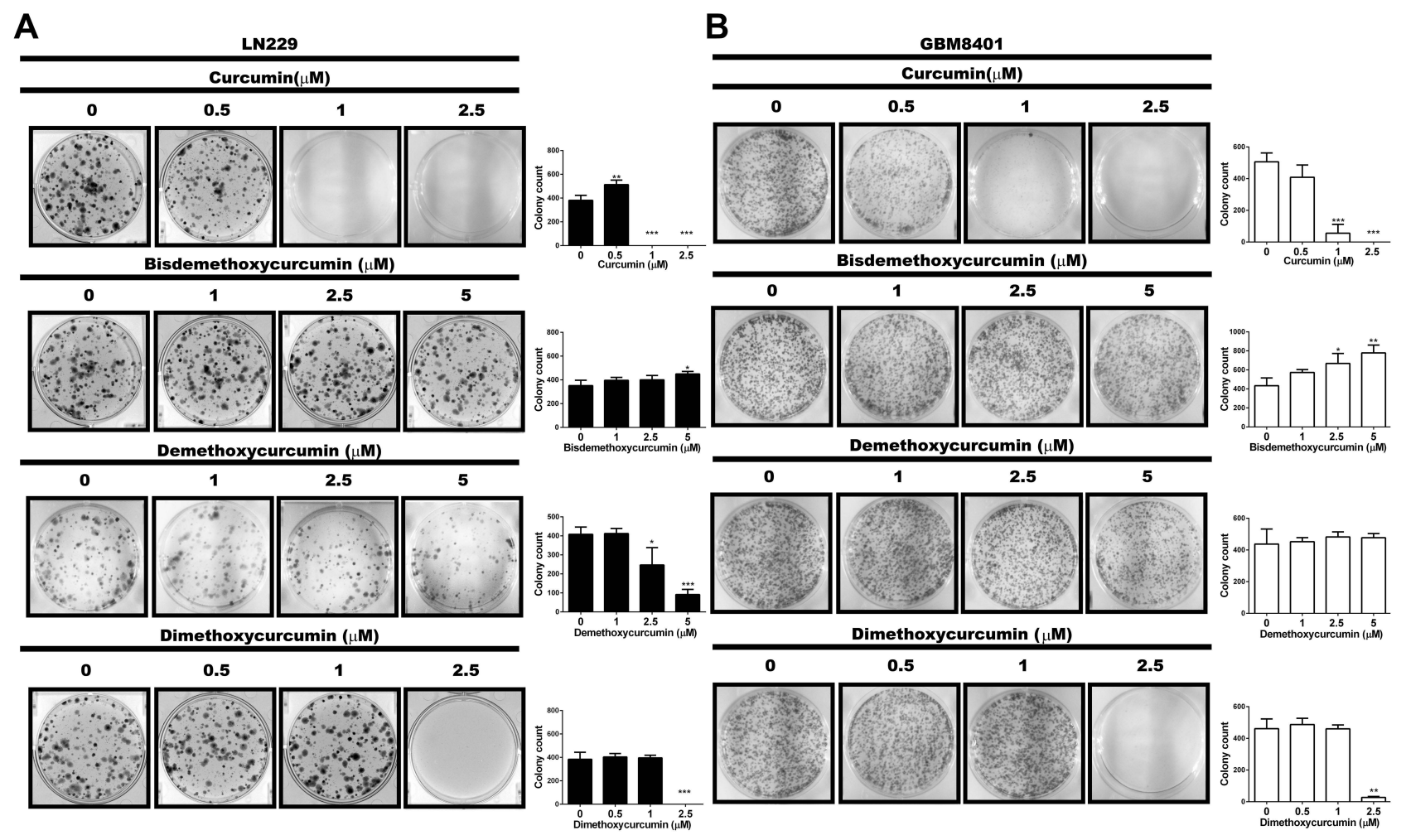

Figure 6 The effect of curcumin analogues on glioma colony formation. (A and B) Images showing colony formation treated with curcumin analogues on LN229 and GBM840I cells. Bar graph showing the effect of curcumin analogues on glioma colony formation. Data are presented as the mean \pm s.d.; $\mathrm{n}=3$; $* \mathrm{P}<0.05, * * \mathrm{P}<0.0 \mathrm{I}$, $* * * \mathrm{P}<0.001$ vs the control.

dimethoxycurcumin than bisdemethoxycurcumin and demethoxycurcumin. Moreover, the effect of induction sub-G1, G2/M arrest and apoptosis in glioma cells is better in demethoxycurcumin than bisdemethoxycurcumin. Consistently, curcumin effects induction of G2/M arrest in medulloblastoma. ${ }^{7}$ A previous study also showed that demethoxycurcumin induces U87MG cell line apoptosis and $\mathrm{G} 2 / \mathrm{M}$ arrest through BCL-2. ${ }^{20}$ In addition, bisdemethoxycurcumin also induced $\mathrm{G} 2 / \mathrm{M}$ arrest in breast cancer cells. ${ }^{21}$ Previous studies showed that curcumin, bisdemethoxycurcumin, and demethoxycurcumin induced apoptosis, ROS production, and inhibited proliferation in leukemia, breast cancer, prostate carcinoma, and lung cancer cells. ${ }^{8,21,22}$ Furthermore, our study showed that the anti-cancer activities of these four curcumin analogues were the strongest in curcumin than in dimethoxycurcumin, followed by demethoxycurcumin, and bisdemethoxycurcumin (ie, curcumin $>$ dimethoxycurcumin $>$ demethoxycurcumin $>$ bisdemethoxycurcumin) in LN229 and GBM8401 glioma cells.

Our results showed that the $\mathrm{IC}_{50}$ of curcumin in SVG p12 is only $4.19 \mu \mathrm{M}$. SVG p12 is a human fetal glial cell line, NHA cells were acquired from human brain tissue,
LN229 and GBM8041 cell line were obtained from 31 and 60 -year-old female patient. Our results showed that different curcumin analogues have different $\mathrm{IC}_{50}$ for normal cell controls and glioma cells.

Different from gliomas, demethoxycurcumin and dimethoxycurcumin had less cytotoxicity in SVG p12, and the cytotoxicity of curcumin and dimethoxycurcumin were higher in NHA. Compare to glioma cell lines, normal cell controls have more unstable growth conditions. Some references showed that SVG p12 can bear $25 \mu \mathrm{M}$ or even higher curcumin, ${ }^{23,24}$ another reference reveals that SVG p12 cells had been infected with BK polyomavirus and lead to mutate at least since $2006,{ }^{25}$ which may cause our results unexpected.

Our study showed that bisdemethoxycurcumin increased apoptosis more in GBM8401 than in LN229 glioma cell line. Moreover, demethoxycurcumin reduced the cell proliferation in GBM8401 glioma cells, while demethoxycurcumin increased cell proliferation in LN229 glioma cells. Some previous studies showed that both LN229 and GBM8401 are p53 mutant and pTEN wild type human glioma cell lines, ${ }^{19,26}$ while LN229 cell line still has wild type p53 function, ${ }^{27}$ suggesting the 
A

LN229
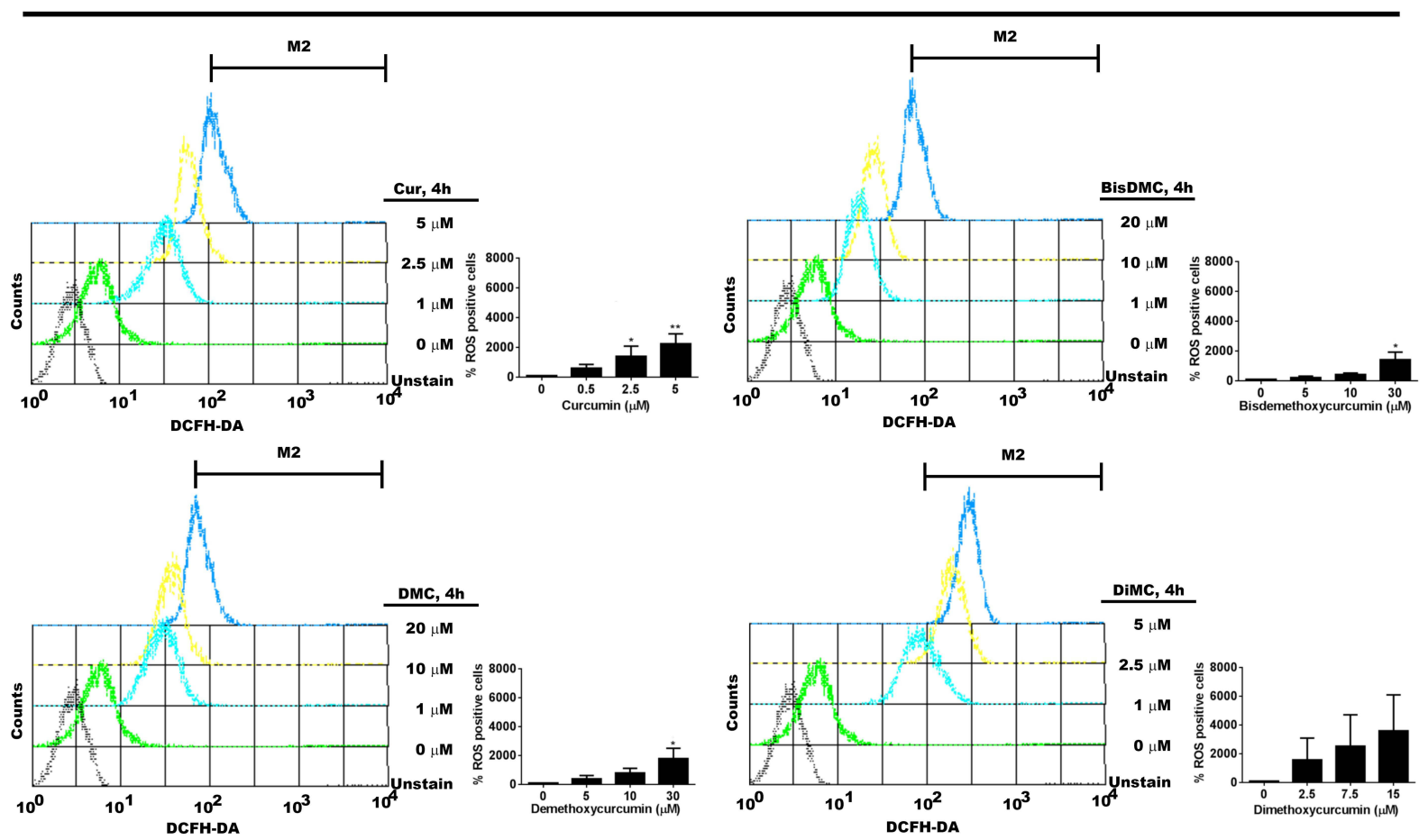

B

\section{GBM8401}
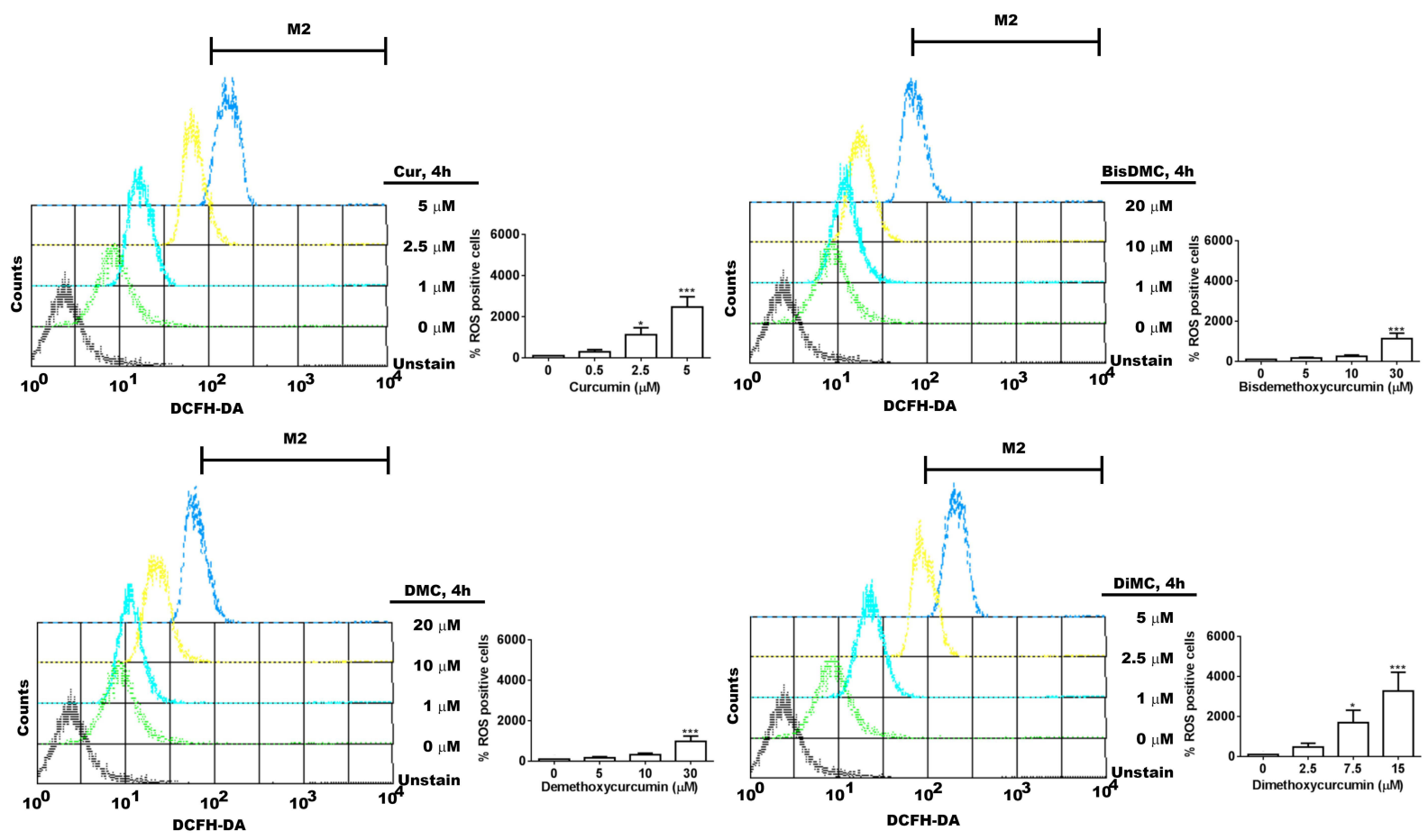

Figure 7 The effect of curcumin analogues on ROS of gliomas. (A and B) Images showing ROS positive percentage treated with $4 \mathrm{~h}$ curcumin analogues on LN229 and $\mathrm{GBm840}$ I cells. Bar graph showed the effect of curcumin analogues on ROS of glioma cells. Data were presented as the mean $\pm \mathrm{s} . \mathrm{d}$.; $\mathrm{n}=3 ; * \mathrm{P}<0.05, * * \mathrm{P}<0.0 \mathrm{I}, * * * \mathrm{P}<0.00 \mathrm{I}$ vs the control. 
A

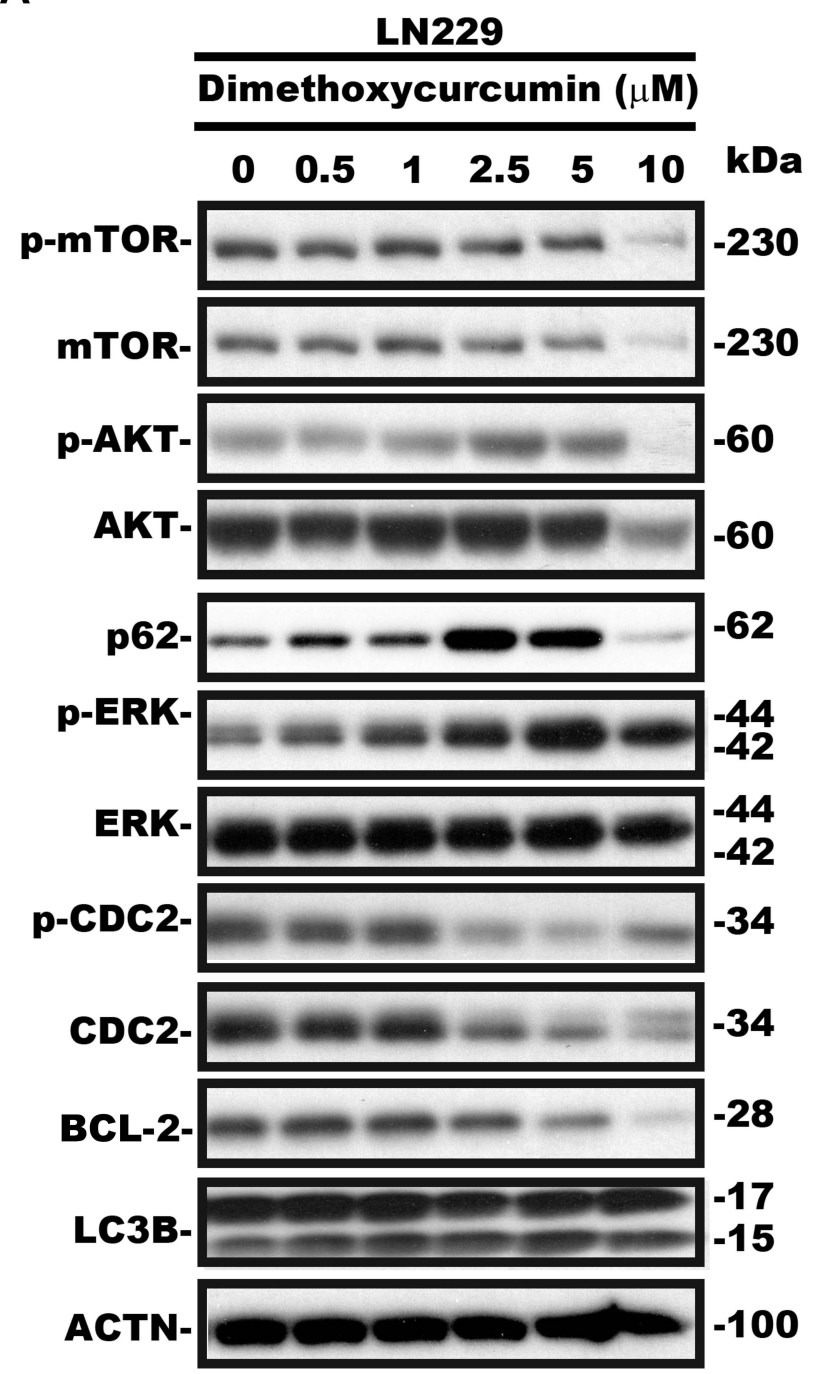

B

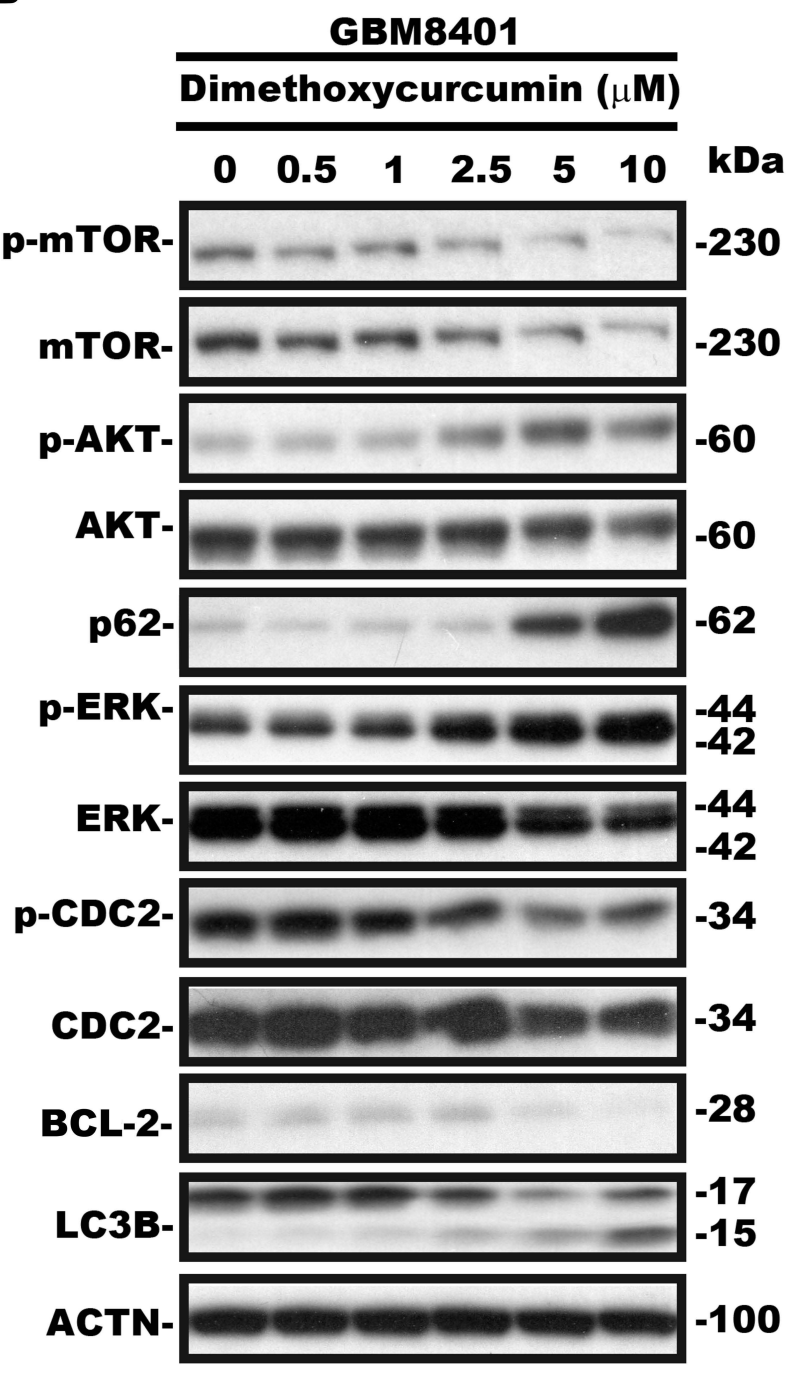

Figure 8 The effect of curcumin analogues on gliomas protein production. (A and B) Western blot analysis of proteins production treated with dimethoxycurcumin $24 \mathrm{~h}$ in LN229 and GBM840I cells.

differential genetic background of human glioma cells might display differential sensitivity to curcumin analogues. Previous study showed that the number of methoxy group effects chemical stability. Since bisdemethoxycurcumin lacks methoxy group. The chemical stability is better in bisdemethoxycurcumin than curcumin and demethoxycurcumin. ${ }^{14}$ In contrast, demethoxycurcumin has one methoxy group, while curcumin has two methoxy groups. Therefore, the chemical stability is better in demethoxycurcumin than in curcumin. ${ }^{28}$ Consistently, methoxy groups of curcumin analogues also played important anti-cancer effects in breast cancer, melanoma, and osteosarcoma. ${ }^{14}$ Furthermore, Somparn et $\mathrm{al}^{29}$ found that methoxy group associated with the antioxidant activity. In our results showed that curcumin, demethoxycurcumin and dimethoxycurcumin displayed the anti-cancer activities such as suppressed cell viability and colony formation in both LN229 and GBM8401 glioma cells. However, low-dose bisdemethoxycurcumin slightly increased cell viability, colony formation, and dose-dependently increased cell proliferation in LN229 and GBM8401 glioma cells. It suggested that methoxy group on the phenyl ring and chemical instability might contribute to cytotoxicity of curcumin analogues to human gliomas.

In general, retinal angiogenesis underwent autophagy displayed the decrease of p62 while the increase of LC3BII. ${ }^{30}$ Our study showed that dimethoxycurcumin increased p62 and LC3B-II in LN229 and GBM8401 glioma cells. $\mathrm{Ni}$ Shen et al found that nanodrug treatment in retinal angiogenesis also increased p62, the possible reason is 
that autophagosomes has not yet completely denatured. They concluded that activated autophagy continues to increase autophagic cell death, despite of autophagosomes is not yet completely degraded. ${ }^{30}$ The ROS downregulated $\mathrm{p}$-AKT expression reduced $\mathrm{p}$-mTOR and increased LC3B-II to induce autophagy. ${ }^{31,32}$ In our results, we found that dimethoxycurcumin increased p-AKT expression and reduced the expression of $\mathrm{p}-\mathrm{mTOR}$ in LN229 and GBM8401 cells. Phosphor-CDC2 is promoted by cyclin kinase inhibitor $\mathrm{p} 21,{ }^{33}$ to inactive cyclin $\mathrm{B} /$ CDC2 complex and caused G2/M phase arrest. ${ }^{34}$ A previous study showed that microinjection of cytochrome $\mathrm{c}$ active AKT to induce caspase activation through inhibit apoptosis while BCL-2-expressing cells do not effect. $^{35}$ In Figure 8, our results showed that dimethoxycurcumin suppressed the expression of apoptosis marker BCL-2, increased sub-G1 and G2/M phase, promoted apoptosis in LN229 and GBM8401 glioma cells. We speculate that there are other factors to cause curcumin analogues to promote apoptosis and autophagy in LN229 and GBM8401 cells. Based on Figures 2, 3, 7 and 8, we found that the mechanism of dimethoxycurcumin is through the production of ROS to increase autophagy, and also induce G2/M arrest and apoptosis in LN229 and GBM8401 glioma cells.

Previous studies showed curcumin has some limitations including metabolic instability, and poor bioavailability, ${ }^{15,16}$ inspiring the new synthesis of curcumin analogues. Moreover, dimethoxycurcumin has higher chemical stability than curcumin and demethoxycurcumin. Cell metabolism is more stable in dimethoxycurcumin than in curcumin. ${ }^{36}$ Dimethoxycurcumin has more methoxy groups, ${ }^{16}$ and metabolically stable, ${ }^{37}$ unstable structure and more hydrophobic than curcumin in terms of structure. ${ }^{16}$ According to the characteristics of the $\mathrm{BBB}$, the hydrophobic drugs are prone to pass through the $\mathrm{BBB}$ than hydrophilic drugs. ${ }^{38}$ Based on the aforementioned characteristics, this study suggested that dimethoxycurcumin might improve the limitation of curcumin and serve as an auxiliary drug for glioma patients.

\section{Conclusion}

In this study, we compared the anti-cancer effects of four different curcumin analogues (curcumin, bisdemethoxycurcumin, demethoxycurcumin and dimethoxycurcumin) on cell cycle arrest, apoptosis and ROS production of LN229 and GBM8401 glioma cells. To the best of our knowledge, this is the first study of four curcumin analogues to show that dimethoxycurcumin might act as one of the potential anti-cancer activities involved in induction of apoptosis, autophagy, ROS production, suppression of cell viability, and proliferation in human glioma cells. Our results suggest that the number of methoxy groups of curcumin analogues may be correlated with anti-cancer activity of human glioma cells. Our study provided side by side investigations of curcumin analogues effect on gliomas in vitro. However, further in vivo experiments are warranted to discover the molecular mechanisms of dimethoxycurcumin in human gliomas .

\section{Data Sharing Statement}

All data are included in this article.

\section{Ethics Approval and Informed Consent}

Not applicable.

\section{Consent for Publication}

All participants agreed to publish the study.

\section{Acknowledgments}

We thank the technical services provided by Instrument Center of National Defense Medical Center, Taipei, Taiwan.

\section{Author Contributions}

All authors made a significant contribution to the work reported in the conception, study design, execution, and acquisition of data, analysis and interpretation; took part in drafting, revising, and critically reviewing the article. All authors gave final approval of the version to be published; have agreed on the journal to which the revised manuscript has been resubmitted; and agreed to be accountable for all aspects of the work.

\section{Funding}

This work was supported, in part, by grants from the Ministry of Science and Technology (MOST 106-2314-B-016-012MY3, and MOST 108-2314-B-016-026 -MY3 to D.-Y.H.), Tri-Service General Hospital (TSGH-C107- 008-S05, ATSGH-C107-008-S05, TSGH-C108-007-008-S05, TSGHC01-109016, TSGH-1-C108-106-2314-B-016-012-MY3, and TSGH-C05-110034 to D.-Y.H), and Medical Affairs Bureau, Ministry of National Defense (MAB-106-019, MAB-107-009, MAB-108-022, MAB-109-014, and MAB110-115 to D.-Y.H). 


\section{Disclosure}

The authors report no conflicts of interest in this work.

\section{References}

1. David NL, Arie P, Guido R. The 2016 world health organization classification of tumors of the central nervous system: a summary. Acta Neuropathol. 2016;131:6. doi:10.1007/s00401-016-1545-1

2. Kirsten L, Harley IK. Molecular markers in glioma. J Neurooncol. 2017;134:3. doi:10.1007/s11060-017-2379-y

3. Tsai C-K, Huang L-C, Wu Y-P, Kan I-Y, Hueng D-Y. SNAP reverses temozolomide resistance in human glioblastoma multiforme cells through down-regulation of MGMT. FASEB J. 2019;33:12. doi:10.1096/fj.201901021RR

4. Dewan M, Sakib H, Sankar B, Tanya D, Gaurisankar S. Curcumin: the multi-targeted therapy for cancer regression. Front Biosci. 2012; S4:21. doi:10.2741/272

5. Garcia-Alloza M, Borrelli LA, Rozkalne A, Hyman BT, Bacskai BJ. Curcumin labels amyloid pathology in vivo, disrupts existing plaques, and partially restores distorted neurites in an Alzheimer mouse model. J Neurochem. 2007;102:1095.

6. Song X-Q, Zhang M, Dai E-G, Luo Y. Molecular targets of curcumin in breast cancer. Mol Med Rep. 2019;19. doi:10.2741/272

7. He M-S, Li Y, Zhang L, et al. Curcumin suppresses cell proliferation through inhibition of the Wnt/ $\beta$-catenin signaling pathway in medulloblastoma. Oncol Rep. 2014;32:8. doi:10.3892/or.2014.3206

8. Santosh KS, Manoj KP, Bokyung S, et al. Curcumin, demethoxycurcumin, bisdemethoxycurcumin, tetrahydrocurcumin and turmerones differentially regulate anti-inflammatory and anti-proliferative responses through a ROS-independent mechanism. Carcinogenesis. 2007;28(8):9. doi:10.1093/carcin/bgm123

9. Lin H-Y, Lin J-N, Ma J-W, Yang N-S, Ho C-T, Kuo S-C. Way demethoxycurcumin-induced DNA damage decreases DNA repair-associated protein expression levels in NCI-H460 human lung cancer cells. Anticancer Res. 2015;35:8.

10. Lin -C-C, Kuo C-L, Huang Y-P, et al. Demethoxycurcumin suppresses migration and invasion of human cervical cancer hela cells via inhibition of NF-KB pathways. Anticancer Res. 2018;38:9.

11. Wang H-J, Yang Z-X, Dai X-T, Chen Y-F, Yang H-P. Bisdemethoxycurcumin sensitizes cisplatin-resistant lung cancer cells to chemotherapy by inhibition of CA916798 and PI3K/AKT signaling. Apoptosis. 2017;22:1157-1168. doi:10.21873/anticanres.12519

12. Pei H-F, Yang Y, Cui L, Yang J. Bisdemethoxycurcumin inhibits ovarian cancer via reducing oxidative stress mediated MMPs expressions. Sci Rep. 2016;6(28773):1-8. doi:10.1038/srep28773

13. Qiu C-J, Liu K-R, Zhang S, et al. Bisdemethoxycurcumin inhibits hepatocellular carcinoma proliferation through akt inactivation via CYLD-Mediated deubiquitination. Drug Des Devel Ther. 2020;14:993-1001. doi:10.2147/DDDT.S231814

14. Huang C, Lu H-F, Chen Y-H, Chen J-C, Chou W-H. Curcumin, demethoxycurcumin, and bisdemethoxycurcumin induced caspasedependent and -independent apoptosis via Smad or Akt signaling pathways in HOS cells. BMC Compl Med Therapies. 2020;20:68. doi:10.1186/s12906-020-2857-1

15. Preetha A, Ajaikumar BK, Robert AN, Bharat BA. Bioavailability of curcumin: problems and promises. Mol Pharm. 2007;4:5. doi:10.1021/mp700113r

16. Manouchehr T, Nastaran B, Matteo P, Amirhosein S. Biological and pharmacological evaluation of dimethoxycurcumin: a metabolically stable curcumin analogue with a promising therapeutic potential. $J$ Cell Physiol. 2018;233:1.

17. Ami K, Atanu B, Santosh KS, Indira P K. Differential antioxidant/ pro-oxidant activity of dimethoxycurcumin, a synthetic analogue of curcumin. Free Radic Res. 2011;45:959. doi:10.3109/ 10715762.2011.571681
18. Sundarraj J, Patwardhan RS, Debojyoti P, Deepak S, Santosh KS. Dimethoxycurcumin, a metabolically stable analogue of curcumin enhances the radiosensitivity of cancer cells: possible involvement of ROS and thioredoxin reductase. Biochem Biophys Res Commun. 2016;478:9. doi:10.1016/j.bbrc.2016.06.144

19. Martin T, Peter G, Ursula M, Erich G. Chemosensitivity of human malignant glioma: modulation by p53 gene transfer. J Neurooncol. 1998;39:39. doi:10.1023/a:1005910323338

20. Pratibha ML, Rakesh K, Amresh P. Demethoxycurcumin induces Bcl-2 mediated G2/M arrest and apoptosis in human glioma U87 cells. Biochem Biophys Res Commun. 2009;384:6. doi:10.1016/j. bbrc.2009.04.149

21. Li Y-B, Gao J-L, Zhong Z-F, Hoi P-M, Ming-yuen lee S, Wang Y-T. Bisdemethoxycurcumin suppresses MCF-7 cells proliferation by inducing ROS accumulation and modulating senescence-related pathways. Pharmacol Rep. 2013;65:10. doi:10.1016/s1734-1140(13)71048-x

22. Yonika Arum L, Yoneda-K N, Ikuko N, Takashi Y, Edy M, Jun-ya K. Curcumin targets multiple enzymes involved in the ROS metabolic pathway to suppress tumor cell growth. Sci Rep. 2018;8:1. doi:10.1038/s41598-018-20179-6

23. Mirna A, Romero H, Pilar E-A. Toxic effects induced by curcumin in human astrocytoma cell lines. Toxicol Mechanism Methods. 2013;23 (9):10. doi:10.3109/15376516.2013.826768

24. Zhao J, Zhu J-B, Lv X-S. Curcumin potentiates the potent antitumor activity of ACNU against glioblastoma by suppressing the $\mathrm{PI} 3 \mathrm{~K} /$ $\mathrm{AKT}$ and NF-kB/COX-2 signaling pathways. Onco Targets Ther. 2017;10:12. doi:10.2147/OTT.S149708

25. Stian H, Garth DT, Alexis D, Biswa Nath S, Hans HH. The human fetal glial cell line SVG p12 contains infectious BK polyomavirus. J Virol. 2014;88:12. doi:10.1128/JVI.00696-14

26. Chu C-W, Ko H-J, Chou C-H. Thioridazine enhances P62-Mediated autophagy and apoptosis through $\mathrm{Wnt} / \beta$-Catenin signaling pathway in glioma cells. Int J Mol Sci. 2019;20(3):473. doi:10.3390/ ijms 20030473

27. Kang K-B, Zhu C-G, Yong S-K, Gao Q-H, Wong M-C. Enhanced sensitivity of celecoxib in human glioblastoma cells: induction of DNA damage leading to p53-dependent G1 cell cycle arrest and autophagy. Mol Cancer. 2009;8:66. doi:10.1186/1476-4598-8-66

28. Han G, Cui -J-J, Bi R, Zhao -L-L. Study on stability of curcumine, demethoxycurcumin and bisdemethoxycurcumin. Chin materia medica. 2008;33(22):2611.

29. Poorichaya S, Chada P, Somjai N, Supeenun U, Noppawan Phumala M. Comparative antioxidant activities of curcumin and its demethoxy and hydrogenated derivatives. Biol Pharm Bull. 2007;30:1. doi:10.1248/bpb.30.74

30. Ni Shen RZ, Zhang H-R, Luo H-Y, et al. Inhibition of retinal angiogenesis by gold nanoparticles via inducing autophagy. Int J Ophthalmol. 2018;11:8.

31. Wang X-Z, Jia Z, Yang -H-H, Liu Y-J. Dibenzoxanthenes induce apoptosis and autophagy in HeLa cells by modeling the PI3K/Akt pathway. J Photochem Photobiol Biol. 2018;187:76. doi:10.1016/j. jphotobiol.2018.08.001

32. Gao X, Yang J-GH, Li Y-Q, Yu M, Lu X-B, Jin C-H. Lanthanum chloride induces autophagy in rat hippocampus through ROS-mediated JNK and AKT/mTOR signaling pathways. Metallomics. 2019;11:2. doi:10.1039/c8mt00295a

33. Andrei LG, Angela LT. The role of the cyclin-dependent kinase inhibitor p21 in apoptosis. Mol Cancer Therapeutic. 2002;1:8.

34. Zhang X-H, Zou Z-Q, Ch-W X, Shen Y-Z, Li D. Myricetin induces G2/M phase arrest in HepG2 cells by inhibiting the activity of the cyclin B/Cdc2 complex. Mol Med Rep. 2011;4:273. doi:10.3892/ mmr.2011.417

35. Zhou H-L, Li X-M, Judy M, Randall NP. Akt Regulates cell survival and apoptosis at a postmitochondrial level. J Cell Biol. 2000;151:3. doi:10.1083/jcb.151.3.483 
36. Constantin T, Konstantinos D, Zacharias DS, Sophia H, Han Z-Y, Liu Z-L. Metabolism and anticancer activity of the curcumin analogue, dimethoxycurcumin. Clin Cancer Res. 2007;13:4. doi:10.1158/ 1078-0432.CCR-06-1839

37. Raghavendra SP, Rahul C, Deepak S, Vineet K, Priyadarsini KI, Santosh KS. Dimethoxycurcumin, a metabolically stable analogue of curcumin, exhibits anti-inflammatory activities in murine and human lymphocytes. Biochem Pharmacol. 2011;82:6. doi:10.1016/j. bcp.2011.06.024
38. Gao W, Liu Y-C, Jing G-X, et al. Rapid and efficient crossing blood-brain barrier: hydrophobic drug delivery system based on propionylated amylose helix nanoclusters. Biomaterials. 2017;113:133. doi:10.1016/j.biomaterials.2016.10.045

\section{Publish your work in this journal}

OncoTargets and Therapy is an international, peer-reviewed, open access journal focusing on the pathological basis of all cancers, potential targets for therapy and treatment protocols employed to improve the management of cancer patients. The journal also focuses on the impact of management programs and new therapeutic agents and protocols on patient perspectives such as quality of life, adherence and satisfaction. The manuscript management system is completely online and includes a very quick and fair peer-review system, which is all easy to use. Visit http://www.dovepress.com/ testimonials.php to read real quotes from published authors. 